\title{
Treatment of noninfectious uveitis
}

\author{
Tratamento das uveítes não-infecciosas \\ Lisia Barros Ferreira' (D), Alexandra L. Farrall', João M. Furtado² (D), Justine R. Smith \\ 1. College of Medicine \& Public Health, Flinders University, Adelaide, Australia. \\ 2. Division of Ophthalmology, Faculdade de Medicina de Ribeirão Preto, Universidade de São Paulo, Ribeirão Preto, SP, Brazil.
}

\begin{abstract}
I Uveitis is a broad term that refers to a large group of eye disorders categorized by intraocular inflammation, a leading cause of visual impairment. Historically, treatment of noninfectious uveitis has depended on corticosteroid drugs. Owing to the myriad of side effects caused by corticosteroids, immunomodulatory therapy has become the preferred treatment for chronic noninfectious intraocular inflammation. Recently, biological response modifiers have established a new era in uveitis therapy, with the range of targets continuing to expand. In this review, we aimed to convey up-to-date information on the treatment of noninfectious uveitis to the general ophthalmologist.
\end{abstract}

Keywords: Uveitis; Noninfectious uveitis; Immunomodulatory therapy; Biologics; Inflammation

RESUMO I Uveíte é um termo amplo utilizado para denominar várias desordens categorizadas como inflamação intraocular, uma causa importante de deficiência visual. Historicamente, o tratamento das uveítes não infecciosas baseou-se no uso de corticosteróides. Devido aos diversos efeitos colaterais do uso de corticosteróides a longo prazo, a terapia imunomoduladora é indicada no tratamento das uveítes não infecciosas crônicas. A introdução dos medicamentos biológicos estabeleceu uma nova era no tratamento das uveítes, com constante desenvolvimento de novas drogas. O objetivo desta revisão é trazer informações atuais sobre tratamento das uveítes não infecciosas para a prática clínica do oftalmologista geral.

Descritores: Uveítes; uveíte não-infecciosa; Terapia imunomodulatória; Biológicos; Inflamação

Submitted for publication: June 25, 2020

Accepted for publication: September 2, 2020

Funding: This study received no specific financial support.

Disclosure of potential conflicts of interest: None of the authors have any potential conflicts of interest to disclose.

Corresponding author: Lisia Barros Ferreira.

E-mail: lisia.ferreira@flinders.edu.au

\section{INTRODUCTION}

Uveitis is one of the leading causes of visual impairment in the Western world ${ }^{(1)}$. The goals of uveitis therapy are to suppress inflammation, achieve inactivity of the disease, and prevent secondary complications that may lead to vision loss. An interdisciplinary clinical team is often required to achieve the most comprehensive and effective care. Corticosteroids are the cornerstone of noninfectious uveitis care ${ }^{(2)}$. Topical, regional, and systemic forms are used, depending on the underlying etiology and clinical presentation of uveitis. When local corticosteroid treatment is insufficient or inappropriate to control intraocular inflammation, systemic corticosteroid therapy is prescribed, but the dose must be tapered as soon as possible owing to the extensive list of possible adverse side effects arising from long-term use. Immunomodulatory therapy should be implemented if prolonged use of corticosteroids is necessary to suppress the inflammation, usually starting with conventional immunomodulatory drugs and adding, or switching to, biologic response modifiers if required ${ }^{(3)}$. Herein, we review the drugs currently used for care of noninfectious uveitis, including delivery and dosing considerations, and side effects.

\section{LOCAL TREATMENT}

\section{Topical treatment}

Topical corticosteroids

Corticosteroids at the top of the inflammatory cascade, downregulating many inflammatory mediators, partly via inhibition of the phospholipase A2 and cyclooxygenase-2 activities $^{(4)}$. Corticosteroid eyedrops are used primarily for anterior uveitis. The administration frequency is defined by the grade of anterior chamber inflammation and may range from every hour to once every other day, usually initiated intensively, with slow 
tapering over weeks to months ${ }^{(3)}$. The commonly used drugs are dexamethasone and prednisolone acetate, the latter reaching higher concentrations in the aqueous hu$\operatorname{mor}^{(5)}$. Difluprednate has been demonstrated to reach the posterior segment at significant concentrations and is effective in the treatment of cystoid macular edema ${ }^{(6,7)}$. Difluprednate causes higher elevations of intraocular pressure $^{(7,8)}$, whereas less potent corticosteroids, such as fluorometholone and loteprednol, have less impact on intraocular pressure but are also not as effective in tackling inflammation ${ }^{(9)}$. Other common side effects of topical corticosteroids include cataract and glaucoma. Table 1 presents the most commonly used topical corticosteroids.

\section{Topical non-steroidal anti-inflammatory drugs}

Topical non-steroidal anti-inflammatory drugs (NSAIDs), which suppress the cyclooxygenase- 1 and 2 enzymes, are not used for managing inflammation in uveitis but may play a role in the treatment of cystoid macular edema secondary to uveitis ${ }^{(10)}$. Although rare, corneal melting and perforation have been described as adverse reactions $^{(11)}$.

\section{Topical cycloplegics}

Tropicamide, cyclopentolate, and atropine are cycloplegic drops prescribed to reduce ciliary spasm and the associated ocular pain and photophobia, and to prevent the development of posterior synechiae in the setting of anterior uveitis ${ }^{(3)}$. Cyclopentolate should be used cautiously in young children under 6 years because of the risk of central nervous system disturbances ${ }^{(12)}$. The duration of cycloplegia for each drug is described in table 2. Tropicamide has a less potent and shorter cycloplegic effect, making it a popular choice ${ }^{(13)}$.

\section{Regional treatment}

Regional corticosteroid treatment is administered as periocular or intraocular injections, or intraocular implants to treat the posterior segment of the eye. This has the advantage of not exposing the patient to systemic complications and is commonly used for unilateral uveitis. Table 3 shows injected and implanted corticosteroids and their associated side effects.

\section{Periocular corticosteroids}

Periocular corticosteroid injections include subtenon and orbital floor approaches. In the posterior subtenon approach, a superotemporal injection of triamcinolone acetonide is given, with effects usually lasting for 3-4 months ${ }^{(14)}$. Periocular corticosteroids may take 2 to 6 weeks to achieve the maximum therapeutic effect and so are not the optimal choice when control of inflammation is urgent ${ }^{(15)}$. Eyelid ptosis, periocular hemorrhage, and globe perforation are the main reported risks ${ }^{(16)}$. Orbital floor injections may induce orbital fat herniation $^{(17)}$. Posterior subtenon corticosteroid injections are effective in treating uveitic macular edema in $>50 \%$ of patients within 3 months ${ }^{(14)}$. An intraocular pressure of $\geq 24 \mathrm{mmHg}$ has been reported in approximately half of patients, with approximately $2 \%$ and $14 \%$ requiring glaucoma and cataract surgery, respectively, within 12 months ${ }^{(15)}$. Subconjunctival dexamethasone attains high

Table 1. Topical corticosteroids and their side effects

\begin{tabular}{lc}
\hline Drug & \multicolumn{1}{c}{ Side effects } \\
\hline Prednisolone acetate 1\% & $\begin{array}{c}\text { Ocular hypertension, } \\
\text { glaucoma, cataract, ocular } \\
\text { surface infections, and eyelid } \\
\text { skin atrophy }\end{array}$ \\
\hline $\begin{array}{l}\text { Prednisolone sodium phosphate 1\% } \\
0.1 \% \text { and ointment } 0.05 \%\end{array}$ & \\
\hline Difluprednate $0.05 \%$ & \\
Fluorometholone suspension $0.1 \%$ and $0.25 \%$ & \\
and ointment $0.1 \%$ & \\
\hline
\end{tabular}

Table 2. Cycloplegic agents, duration of cycloplegia, dosing, and side effects

\begin{tabular}{|c|c|c|c|}
\hline Drug & $\begin{array}{l}\text { Duration of } \\
\text { cycloplegia }\end{array}$ & Dosing & Side effects \\
\hline Tropicamide $1 \%$ & 2-6 hours & 2-4 times daily & \multirow{3}{*}{$\begin{array}{l}\text { Conjunctival } \\
\text { hyperemia, } \\
\text { photophobia, } \\
\text { blurred vision, and } \\
\text { neurologic side } \\
\text { effects (in children) }\end{array}$} \\
\hline $\begin{array}{l}\text { Cyclopentolate } 0.5 \% \\
\text { and } 1 \%\end{array}$ & 12-24 hours & 2-4 times daily & \\
\hline Atropine $0.5 \%$ and $1 \%$ & 7-14 days & 1-2 times daily & \\
\hline
\end{tabular}

Table 3. Periocular and intraocular corticosteroid compounds and side effects

\begin{tabular}{|c|c|c|}
\hline Administration & Compound & Side effects \\
\hline $\begin{array}{l}\text { Periocular - posterior } \\
\text { subtenon }\end{array}$ & $\begin{array}{l}\text { Triamcinolone acetonide } \\
\qquad 40 \mathrm{mg} / \mathrm{mL}\end{array}$ & \multirow{2}{*}{$\begin{array}{l}\text { Ptosis, periocular } \\
\text { hemorrhage, chemosis, } \\
\text { globe perforation, and } \\
\text { orbital fat herniation }\end{array}$} \\
\hline Periocular - orbital floor & $\begin{array}{l}\text { Triamcinolone acetonide } \\
\qquad 40 \mathrm{mg} / \mathrm{mL}\end{array}$ & \\
\hline Intraocular & $\begin{array}{c}\text { Triamcinolone acetonide } \\
2-4 \mathrm{mg} / 0.05-0.1 \mathrm{~mL}\end{array}$ & \multirow{2}{*}{$\begin{array}{c}\text { Ocular hypertension, } \\
\text { cataract, retinal } \\
\text { detachment, vitreous } \\
\text { hemorrhage, and } \\
\text { endophthalmitis }\end{array}$} \\
\hline Intravitreal implant & $\begin{array}{l}\text { Fluocinolone } 0.59 \mathrm{mg} \\
\text { (Retisert) } \\
\text { Fluocinolone } 0.19 \mathrm{mg} \\
\text { (lluvien) } \\
\text { Dexamethasone } 0.7 \mathrm{mg} \\
\text { (Ozurdex) }\end{array}$ & \\
\hline
\end{tabular}


concentrations in aqueous humor but unsatisfactory diffusion to the vitreous ${ }^{(18)}$.

\section{Intravitreal corticosteroids}

Intravitreal injections of corticosteroids are preferred to obtain a rapid anti-inflammatory effect and treat macular edema refractory to periocular corticosteroids. Triamcinolone acetonide is administered via pars plana injection with a 27-gauge needle, with therapeutic effects lasting for 3-6 months in non-vitrectomized eyes ${ }^{(19)}$. The intraocular pressure may start to increase 1 week after the intravitreal injection procedure and may remain elevated for up to 9 months, with children being more prone ${ }^{(20)}$. Up to $100 \%$ of eyes treated with intravitreal triamcinolone need topical or systemic anti-glaucoma therapy, and small numbers will require filtering surgery ${ }^{(20,21)}$. Posterior subcapsular cataract may develop and progress in $50 \%$ of cases $^{(22)}$. Sterile endophthalmitis is reported in up to $4.6 \%$ of cases of intravitreal triamcinolone injection, mostly when preserved and small particle formulations are used ${ }^{(23)}$. As with any other intraocular procedure, intravitreal injection also carries a risk of infectious endophthalmitis.

Corticosteroid implants were developed to last for long durations and to achieve effective concentrations of drugs inside the eye. Retisert (Bausch and Lomb, Inc.), the first implantable corticosteroid released in 2005 for the treatment of chronic noninfectious uveitis, is composed of $0.59 \mathrm{mg}$ of fluocinolone acetonide and implanted via a small pars plana incision, with a therapeutic effect lasting up to 30 months $^{(24)}$. Within 24 months, a substantial proportion of eyes require pressure-lowering medications $(60 \%)$ or filtering surgery (25\%). Cataract surgery is required in $80 \%$ of eyes ${ }^{(24)}$. Displaying a safer profile, Ozurdex ${ }^{\circledR}$ (Allergan) is an implant containing $0.7 \mathrm{mg}$ of dexamethasone administered via pars plana injection with a 22-gauge needle applicator, and its effects last up to 6 months ${ }^{(25)}$. During this time, $7 \%$ of eyes have increased intraocular pressure $(\geq 25 \mathrm{mmHg})$ and $15 \%$ develop cataract ${ }^{(25)}$. Corticosteroid implants should be avoided in patients with aphakia and/or a displaced intraocular lens as a result of the risk of implant migration to the anterior chamber. Intravitreal dexamethasone implant or intravitreal triamcinolone injection are superior to posterior subtenon triamcinolone injection for the treatment of uveitic macular edema ${ }^{(26)}$.

Approved for diabetic macular edema treatment in 2014, the lluvien implant (pSivida Corp; 0.19 mg fluo- cinolone acetonide), inserted using a 25-gauge needle applicator, may provide 36 months of sustained release of fluocinolone. Increased intraocular pressure and cataract are reported in $37 \%$ and $43 \%$ of patients, respectively ${ }^{(27)}$. Yutiq (Eyepoint Pharmaceuticals) is a microinsert containing $0.18 \mathrm{mg}$ of fluocinolone acetonide, which is also available for the treatment of noninfectious posterior segment intraocular inflammation ${ }^{(28)}$.

\section{Other intravitreal drugs}

Several drugs that are usually administered systemically (see below) have been also delivered intravitreally. Intravitreal methotrexate $(400 \mu \mathrm{g} / 0.1 \mathrm{~mL})$ injections, a treatment initially developed for ocular involvement in primary central nervous system lymphoma ${ }^{(29,30)}$, is an option that may effectively control intraocular inflammation and induce long periods of remission ${ }^{(31)}$. Intravitreal sirolimus (440 $\mu \mathrm{g} / 0.02 \mathrm{~mL})$ has been studied for the treatment of noninfectious intermediate and posterior uveitis and was shown to control inflammation in around $50 \%$ of patients ${ }^{(32)}$.

\section{SYSTEMIC TREATMENT}

\section{Systemic corticosteroids}

Systemic corticosteroids are effective and widely used despite their broad range of side effects. When topical or regional treatments are insufficient or not appropriate to control intraocular inflammation, systemic corticosteroid therapy is initiated. Depending on the severity of the clinical presentation, oral prednisone at an initial dose of $1 \mathrm{mg} / \mathrm{kg} /$ day, with tapering over approximately 3 months, should be used in an individualized manner(3). Pulse therapy with intravenous methylprednisolone (1 g/ day for 3 days) may be used for severe sight-threatening cases such as the acute presentation of Vogt-KoyanagiHarada (VKH) syndrome ${ }^{(33)}$. This intravenous therapy is followed by a course of oral prednisone therapy.

Complications include osteoporosis, diabetes mellitus, systemic hypertension, weight gain, mood changes, peptic ulcer, pancreatitis, hirsutism, femoral head osteonecrosis, infections, cataracts, and glaucoma ${ }^{(34)}$. Growth retardation is a specific concern in children who receive long-term treatment. Patients taking chronic doses of corticosteroids should take vitamin D and calcium supplements to mitigate bone density loss, and may require histamine- 2 receptor blockers or proton pump inhibitors for gastroesophageal protection. 


\section{Systemic non-steroidal anti-inflammatory drugs}

Systemic NSAIDs are not generally used in the treatment of uveitis. However, a role has been suggested in the prevention of ocular inflammation, particularly when used in combination with tumor necrosis factor (TNF)- $\alpha$ blocking drugs in patients with ankylosing spondylitis ${ }^{(35)}$.

\section{Immunomodulatory therapy}

When an oral prednisone dose $>5 \mathrm{mg} /$ day is required beyond 3 months or when inflammation persists despite corticosteroid use or corticosteroid use is not tolerable, immunomodulatory therapy is the next treatment approach $^{(36)}$. Immunomodulators modify the immune response through different pathways in conjunction with the corticosteroid-sparing effect. As it may take several weeks to months for immunomodulatory therapy to control inflammation, concomitant corticosteroid use is advised until the full effect is achieved.

Immunomodulatory therapy is divided into conventional and biologic response modifier drugs. Biologic response modifiers, or "biologics", are a class of immunomodulatory drugs that target different inflammatory molecules such as interleukins (IL) and TNF- $\alpha$. Biologic response modifiers are usually second-line to the conventional immunomodulatory drugs for the treatment of recalcitrant cases of noninfectious uveitis.

A thorough clinical history taking and laboratory assessment should be performed before initiating immunomodulatory treatment, with close monitoring during follow-up ${ }^{(36)}$. Baseline blood cell counts, and liver and renal functions must be assessed, along with evaluation to rule out active or latent infectious diseases such as tuberculosis. Personal and familial histories of cancer should be determined. An increased risk of malignancy, particularly non-melanoma skin cancer and non-Hodgkin lymphoma, has been reported in a uveitic population treated with immunomodulatory therapy ${ }^{(37)}$. However, the recently communicated results of a multicenter study indicated no increased risk of overall or cancer-related mortality among patients with uveitis who were receiving common immunomodulatory drugs, including TNF- $\alpha$ inhibitors ${ }^{(38)}$.

Specific vision-threatening conditions, such as VKH syndrome, sympathetic ophthalmia, and Behçet's disease, allow for the early introduction of immunomodulatory therapy. Other common indications for early use of immunomodulatory drugs include serpiginous choroiditis, birdshot retinochoroidopathy, multifocal choroiditis, and juvenile idiopathic arthritis (JIA)-associated uveitis ${ }^{(3)}$.

When an immunomodulatory drug is not effective in suppressing inflammation, the dose may be increased to the maximum tolerated, or the drug may be combined with or replaced by another drug. The frequent combinations are antimetabolites with T-cell signaling inhibitors or biologic agents ${ }^{(34,39)}$. Simultaneous use of two immunomodulatory drugs from the same category is not recommended because of the increased risk of side effects. Intraocular inflammation should be inactive for at least 2 years before tapering and withdrawing the immunomodulatory therapy ${ }^{(3)}$. The conventional and biologic immunomodulatory drugs used to treat uveitis are presented in tables 4 and 5, respectively.

\section{Conventional immunomodulatory drugs \\ Antimetabolites}

Antimetabolites act by interfering with DNA synthesis and consequently impairing T- and B-cell development ${ }^{(4)}$. The commonly used drugs in this category are methotrexate, mycophenolate mofetil, and azathioprine. In comparison to methotrexate, leflunomide is less frequently used in the treatment of uveitis and has been associated with more recurrences in patients with JIA-associated uveitis ${ }^{(40)}$. Gastrointestinal side effects are the most frequent complaints. Serious complications include hepatotoxicity, pancreatitis, pulmonary fibrosis, myelosuppression, infection, and phototoxicity ${ }^{(41-43)}$.

Methotrexate inhibits dihydrofolic acid reductase, interfering with folic acid metabolism and DNA synthesis ${ }^{(4)}$. It is effective for the treatment of a spectrum of noninfectious uveitis subtypes ${ }^{(41,42)}$. A study that compared retention time across conventional systemic immunomodulatory drugs in patients with inflammatory eye disease suggested that methotrexate provided superior effectiveness and tolerability ${ }^{(44)}$. In the Systemic Immunosuppressive Therapy for Eye Disease (SITE) Cohort Study, complete control of uveitis was reported in approximately two-thirds of patients treated with methotrexate and $\leq 10 \mathrm{mg}$ daily of prednisone within 1 year of systemic treatment ${ }^{(41)}$. Myelosuppression side effects are limited by folic acid supplementation.

Mycophenolate mofetil is a prodrug of mycophenolic acid that suppresses guanosine nucleotide synthesis ${ }^{(4)}$. The effectiveness of this drug has been shown in many forms of uveitis ${ }^{(45)}$. The SITE Cohort Study showed that mycophenolate mofetil was effective in con- 
Table 4. Conventional immunomodulatory therapy dosing and side effects

\begin{tabular}{|c|c|c|c|}
\hline Class & Drug & Dosing & Side effects \\
\hline \multirow[t]{4}{*}{ Antimetabolites } & Methotrexate & $\begin{array}{c}\text { Initial dose of } 7.5-15 \mathrm{mg} / \text { week; up to } 25 \mathrm{mg} / \text { week } \\
\text { PO/SC }\end{array}$ & $\begin{array}{l}\text { Gl symptoms, liver toxicity, pulmonary fibrosis, } \\
\text { myelosuppression, infection, and phototoxicity }\end{array}$ \\
\hline & Mycophenolate mofetil & 1-2 g/day PO in divided doses & Gl symptoms, hepatotoxicity, infection, and myelosuppression \\
\hline & Azathioprine & $1-3 \mathrm{mg} / \mathrm{kg} /$ day PO & $\begin{array}{l}\text { Gl symptoms, myelosuppression, infection, alopecia, } \\
\text { hepatotoxicity, and pancreatitis }\end{array}$ \\
\hline & Leflunomide & 20 mg/day PO & Gl symptoms, hepatotoxicity, and skin rashes \\
\hline \multirow[t]{2}{*}{ T-cell inhibitors } & Cyclosporine & $2-3 \mathrm{mg} / \mathrm{kg} /$ day PO in divided doses & $\begin{array}{c}\text { Tremor, myelosuppression, nephrotoxicity, Gl symptoms, } \\
\text { arterial hypertension, hirsutism, female reproductive } \\
\text { disorder, and gum hyperplasia }\end{array}$ \\
\hline & Tacrolimus & $0.1-0.2 \mathrm{mg} / \mathrm{kg} /$ day $\mathrm{PO}$ in divided doses & $\begin{array}{c}\text { Tremor, Gl symptoms, arterial hypertension, peripheral edema, } \\
\text { infection, and nephrotoxicity }\end{array}$ \\
\hline \multirow[t]{2}{*}{ Alkylating agents } & Cyclophosphamide & $2-3 \mathrm{mg} / \mathrm{kg} /$ day PO & $\begin{array}{l}\text { Gl symptoms, myelosuppression, hemorrhagic cystitis, } \\
\text { bladder carcinoma, infection, and infertility }\end{array}$ \\
\hline & Chlorambucil & $0.1-0.2 \mathrm{mg} / \mathrm{kg} / \mathrm{day} \mathrm{PO}$ & $\begin{array}{l}\text { Gl symptoms, myelosuppression, Stevens-Johnson syndrome, } \\
\text { secondary malignancies, infection, and infertility }\end{array}$ \\
\hline Other & Sulfasalazine & $2 \mathrm{~g} /$ day $\mathrm{PO}$ in divided doses & Gl symptoms, blood dyscrasias, and skin rashes \\
\hline
\end{tabular}

$\mathrm{PO}=$ oral; $\mathrm{SC}=$ subcutaneous; $\mathrm{Gl}=$ gastrointestinal.

Table 5. Biologic response modifiers, composition, and side effects

\begin{tabular}{|c|c|c|c|}
\hline Class & Drug & Composition & Side effects \\
\hline \multirow[t]{4}{*}{ Anti-TNF $\alpha$} & Infliximab & Chimeric monoclonal $\mathrm{Ab}$ & $\begin{array}{l}\text { Skin rash, lupus-like illness, vascular thrombosis, congestive } \\
\text { heart failure, demyelinating disorders, infections, tuberculosis } \\
\text { reactivation, and non-melanoma skin cancers }\end{array}$ \\
\hline & Adalimumab & Human monoclonal Ab & $\begin{array}{l}\text { Anaphylaxis, liver toxicity, lupus-like disease, demyelinating } \\
\text { disorders, infections, and tuberculosis reactivation }\end{array}$ \\
\hline & Golimumab & Human monoclonal $\mathrm{Ab}$ & Skin rash, infections, paresthesia, and hepatotoxicity \\
\hline & Certolizumab & Pegylated humanized monoclonal Ab & $\begin{array}{l}\text { Skin rash, Stevens-Johnson syndrome, lupus-like disease, } \\
\text { infections, and malignancies }\end{array}$ \\
\hline \multirow[t]{2}{*}{ Anti-IL-1 $\beta$} & Anakinra & Recombinant receptor antagonist & Gl symptoms, hepatotoxicity, and infections \\
\hline & Canakinumab & Human monoclonal Ab & $\begin{array}{l}\text { Gl symptoms, hepatotoxicity, nephrotoxicity, hypersensitivity } \\
\text { reactions, and infections }\end{array}$ \\
\hline \multirow[t]{2}{*}{ Anti-IL-6 } & Tocilizumab & Humanized monoclonal Ab (receptor targeted) & $\begin{array}{l}\text { Gl symptoms, infections, hepatotoxicity, hyperlipidemia, } \\
\text { neutropenia, thrombocytopenia, pancreatitis, and anaphylaxis }\end{array}$ \\
\hline & Sarilumab & Human monoclonal Ab (receptor targeted) & Infections, myelosuppression, and hepatotoxicity \\
\hline Anti-IL-17A & Secukinumab & Human monoclonal Ab & Gl symptoms, infectious, and urticaria \\
\hline Anti-CD20 & Rituximab & Chimeric monoclonal $\mathrm{Ab}$ & $\begin{array}{l}\text { Infusion reactions, infections, and progressive multifocal } \\
\text { leukoencephalopathy }\end{array}$ \\
\hline \multirow[t]{3}{*}{ Interferons } & IFN $\alpha-2 \mathrm{a}$ & Recombinant human protein & \multirow{3}{*}{$\begin{array}{l}\text { Gl symptoms, hair loss, thyroid, infections, dysfunction, } \\
\text { depression, leukopenia, thrombocytopenia, and hepatotoxicity }\end{array}$} \\
\hline & IFN $\alpha-2 b$ & Recombinant human protein & \\
\hline & IFN $\beta$ & Recombinant human protein & \\
\hline \multirow[t]{2}{*}{ Other } & Intravenous immunoglobulin & Human polyclonal lgG & Eczema, hyperthermia, systemic hypertension, and thrombosis \\
\hline & Abatacept & Fusion protein & \\
\hline
\end{tabular}

Varying dosing schedules are used and continue to be adjusted according experience in their use for the treatment of uveitis increases.

$\mathrm{TNF}=$ tumor necrosis factor; $\mathrm{IL}=$ interleukin; $\mathrm{IFN}=$ interferon; $\mathrm{Ab}=$ antibody; $\mathrm{IV}=$ intravenous; $\mathrm{SC}=$ subcutaneous; $\mathrm{Gl}=$ gastrointestinal .

trolling inflammation in approximately three-quarters of patients with noninfectious uveitis at 12 months of treatment, although most patients still required corticosteroid treatment ${ }^{(45)}$. Gangaputra et al. ${ }^{(42)}$ suggested that mycophenolate mofetil might be faster than methotrexate in achieving corticosteroid-sparing success.

Azathioprine is a prodrug of 6-mercaptopurine, an analogue of the nucleoside purine ${ }^{(4)}$. Thiopurine 
S-methyltransferase is an enzyme involved in azathioprine metabolism. Genetic mutation(s) may result in a deficiency of this enzyme that places the patient at risk of side effects due to increased serum levels of azathioprine ${ }^{(46)}$. Sustained control of uveitis was achieved within 12 months in approximately $60 \%$ of the patients in the SITE Cohort Study who received azathioprine for uveitis, with a relatively high effectiveness in patients with intermediate uveitis $(90 \%)^{(43)}$.

\section{T-cell signaling inhibitors}

Cyclosporine and tacrolimus suppress calcineurin ${ }^{(4)}$, and sirolimus interferes with the mammalian target of rapamycin receptor to downregulate T-cell activity and suppress the expressions of inflammatory cytokines ${ }^{(4,32)}$. Complications include myelosuppression, renal toxicity, gastrointestinal symptoms, systemic hypertension, hirsutism, and gum hyperplasia.

Cyclosporine has a history of use in the treatment of Behçet's disease but is also used for many other forms of noninfectious uveitis ${ }^{(47)}$. More than $50 \%$ of patients may achieve inflammation control within the first year, and approximately $10 \%$ of patients discontinue treatment owing to toxicity ${ }^{(47)}$.

Tacrolimus shares a similar efficacy to cyclosporine (68\%) and may have a lower incidence rate of side effects when used to manage noninfectious intermediate and posterior uveitis ${ }^{(48)}$.

\section{Alkylating agents}

Alkylating agents inhibit DNA replication, limiting the activity of T- and B-cells ${ }^{(4)}$. Cyclophosphamide and chlorambucil are not commonly used, being mostly reserved for cases refractory to antimetabolites and T-cell signaling inhibitors, and recently, to biologic response modifiers because of its serious risks, including infertility and malignancy. Alkylating agents also carry a risk of myelotoxicity and infections.

Cyclophosphamide metabolites alkylate the DNA nucleotide guanine, inhibiting DNA replication ${ }^{(4)}$. More than $60 \%$ of patients treated with cyclophosphamide achieved remission of noninfectious uveitis within 1 year, but the drug was discontinued in around onethird of the patients as a consequence of adverse side effects $^{(49)}$. One product of cyclophosphamide metabolism is acrolein, a carcinogenic substance excreted in urine; therefore, this treatment carries the risks of hemorrhagic cystitis and bladder carcinoma ${ }^{(4)}$.
Chlorambucil produces DNA crosslinking that inhibits cellular replication and induces apoptosis ${ }^{(4)}$. It is usually prescribed for a short period owing to malignancy risk ${ }^{(50)}$. However, results from the largest cohort of patients with uveitis who underwent high-dose chlorambucil therapy during a short-term period showed no malignancies after almost 9 years of mean follow-up ${ }^{(50,51)}$.

\section{Others}

Sulfasalazine, a conjugated molecule of sulfapyridine and 5-aminosalicylate, inhibits prostaglandin synthesis ${ }^{(52)}$. It was evaluated in a small cohort of patients with ankylosing spondylitis-associated anterior uveitis, and the results indicated fewer uveitis recurrences after sulfasalazine therapy, although the grading system used to categorize uveitis activity is no longer used ${ }^{(52)}$.

\section{Biologic response modifiers}

\section{Antitumor necrosis factor alpha}

Tumor necrosis factor alpha is a cytokine produced by multiple leukocyte subsets and other cell populations that activates several inflammatory pathways ${ }^{(4)}$. Multiple biological response modifiers target TNF- $\alpha$, but most experiences in the treatment of uveitis have been with infliximab and adalimumab. Adverse reactions to these drugs include skin rash, lupus-like illness, liver toxicity, systemic vascular thrombosis, congestive heart failure, demyelinating disorders, anaphylaxis, and malignancies $^{(53,54)}$. However, data from large numbers of patients with inflammatory bowel disease suggest no increase in the incidence rates of malignancy with anti-TNF- $\alpha$ drugs ${ }^{(55)}$. This issue continues to be investigated in relation to uveitis.

Infliximab is a chimeric monoclonal antibody that inhibits TNF- $\alpha$ and is administered intravenously. It has been extensively useed in the treatment of Behçet's disease and is also effective for the treatment of $\mathrm{VKH}$ syndrome, ocular sarcoidosis, HLA-B27-associated uveitis, and retinal vasculitis, with approximately $80 \%$ of patients with noninfectious uveitis achieving clinical remission ${ }^{(53)}$. Infliximab has also been successfully used as a "rescue" therapy after failure of other agents, including adalimumab(56).

Adalimumab is a human monoclonal anti-TNF- $\alpha$ antibody that is delivered subcutaneously. It has similar efficacy with infliximab in the treatment noninfectious uveitis, with some evidence favoring its use over infliximab in JlA-associated uveitis ${ }^{(57,58)}$. Adalimumab has 
been approved for the treatment of noninfectious intermediate and posterior uveitis and panuveitis by the United States Food and Drug Administration. Two phase III, randomized, double-masked, placebo-controlled clinical trials (VISUAL I and VISUAL II) demonstrated its effectiveness in delaying time to treatment failure in patients with active and inactive diseases ${ }^{(59,60)}$. Its effectiveness was also demonstrated in SYCAMORE, a randomized, placebo-controlled trial for children with JIA and active uveitis who received methotrexate with placebo or adalimumab ${ }^{(39)}$. Long-term therapy may be necessary for sustained remission, as a 5-year follow-up report showed that $92 \%$ of patients had to resume adalimumab treatment after its withdrawal ${ }^{(61)}$. VISUAL III, a study including some patients from the VISUAL I and Il cohorts, demonstrated that among patients with active uveitis, $60 \%$ attained ocular inflammation control and $66 \%$ discontinued corticosteroid therapy. Threequarters of patients with inactive uveitis at study entry remained in remission at 78 weeks, with $93 \%$ of the patients being corticosteroid-free ${ }^{(62)}$.

Adalimumab and infliximab have similar long-term retention rates, which means that infliximab does not show a larger discontinuation proportion than adalimumab $^{(63)}$. However, infliximab requires more clinic visits for intravenous administration, which may be problematic for patients to accommodate in their daily routine. Antidrug antibodies may arise in response to infliximab or adalimumab therapy, which may reduce their effectiveness. Methotrexate or azathioprine administered with anti-TNF- $\alpha$ drugs may decrease the production of antidrug antibodies and improve treatment efficacy ${ }^{(64)}$.

Golimumab is a human monoclonal anti-TNF- $\alpha$ antibody, first approved for the treatment of ankylosing spondylitis, rheumatoid arthritis, and psoriatic arthritis $^{(65-68)}$. Successful control of intraocular inflammation has been reported not only in HLA-B27 and JIA-associated uveitis but also in Behçet's disease and other types of recalcitrant noninfectious uveitis.

Certolizumab is a PEGylated, humanized anti-TNF- $\alpha$ monoclonal antigen-binding antibody fragment ${ }^{(69)}$. In patients with spondyloarthritis, it was effective in decreasing the incidence of uveitis flares in a doublemasked, placebo-controlled study ${ }^{(70)}$. A retrospective survey of patients with noninfectious uveitis found reduced frequency of ocular flares and long-term visual function retention rates, with no side effects, after the administration of certolizumab, including cases of antiTNF- $\alpha$ therapy failure ${ }^{(70)}$.
Etanercept is a TNF- $\alpha$ receptor-based drug that is used in the treatment of rheumatoid arthritis and spondyloarthropathies. However, it shows little effectiveness in controlling intraocular inflammation and has been associated with paradoxical uveitis; therefore, its use is not recommended for uveitis therapy ${ }^{(71,72)}$.

\section{Anti-IL-1B}

Canakinumab is a human anti-IL-1 $\beta$ monoclonal antibody, whereas anakinra is a recombinant humanized IL-1 receptor antagonist. Both drugs limit the effect of IL-1 $\beta$, a potent inflammatory cytokine. The effectiveness of both drugs was described in the treatment of Behçet's disease, with gastrointestinal symptoms, infections, and anaphylaxis as reported side effects ${ }^{(73,74)}$.

Gevokizumab is a recombinant humanized antiIL-1 $\beta$ antibody, which despite having shown promising results in severe Behçet's uveitis in a phase ll study, did not progress to clinical application after its effectiveness was not confirmed in randomized, double-masked, placebo-controlled phase 11 trials ${ }^{(75,76)}$. The drug did not decrease the number of uveitis flares in Behçet's disease, although results suggested that vision was preserved and cystoid macular edema was reduced in the first 6 months of treatment.

\section{Anti-IL-6}

Tocilizumab is a humanized monoclonal antibody against the receptor of IL-6, a cytokine with a broad range of inflammatory activities ${ }^{(77)}$. It is administered by intravenous infusion or subcutaneously. Studies of tocilizumab conducted in patients with noninfectious uveitis and macular edema refractory to conventional immunomodulatory drugs, anti-TNF- $\alpha$ agents, and interferons have shown favorable outcomes in Behçet's disease, birdshot retinochoroidopathy, JlA-associated uveitis, sympathetic ophthalmia, ocular sarcoidosis, and idiopathic panuveitis. However, the phase II APTITUDE trial, which assessed tocilizumab in 21 patients with JIA-associated uveitis refractory to antiTNF- $\alpha$ treatment, did not meet the efficacy end point required for phase III trials, despite demonstrating a good safety profile ${ }^{(78)}$. Reported side effects include gastrointestinal symptoms, upper respiratory tract infections, hepatotoxicity, hyperlipidemia, neutropenia, and thrombocytopenia ${ }^{(77,79-81)}$.

Sarilumab is a human anti-IL-6 receptor monoclonal antibody that was found to be well tolerated and 
effective for improving vision, reducing inflammation, and decreasing corticosteroid use in adults with noninfectious uveitis when compared with placebo ${ }^{(82)}$.

\section{Anti-IL-17}

Secukinumab is a human monoclonal anti-IL-17A antibody, available in both intravenous and subcutaneous preparations ${ }^{(83)}$. Three phase IIl clinical trials of subcutaneous administered secukinumab in patients with noninfectious uveitis failed to meet the primary efficacy end points ${ }^{(83)}$. By contrast, the results of a subsequent phase Il clinical trial, which involved intravenous and subcutaneous drug administration, suggested that intravenous secukinumab had therapeutic benefits in patients with uveitis, reducing inflammation in up to $73 \%$ and achieving remission in around a third of all cases, with a good safety profile ${ }^{(84)}$.

\section{Anti-CD2O}

Rituximab is a chimeric monoclonal anti-CD20 antibody that targets B-cells and has been administered intravenously for noninfectious uveitis ${ }^{(85,86)}$. It also has been successfully used in the management of refractory cases of orbital inflammation and scleritis ${ }^{(87,88)}$, and intravitreally for ocular involvement in primary central nervous system lymphoma ${ }^{(30)}$. Rituximab is generally well tolerated, with infusion reactions being the most common adverse event. Infections are surprisingly uncommon. Progressive multifocal leukoencephalopathy is a rare complication.

\section{Interferons}

After binding the cell membrane receptor, interferons initiate signal transduction cascades that stimulate the production of proteins with antiviral and immunomodulatory properties ${ }^{(4)}$. Flu-like symptoms are the commonly reported side effects of interferon, but severe adverse events are rare. Other reported complications are gastrointestinal disturbance, hair loss, dysthyroidism, depression, leukopenia, thrombocytopenia, and elevated liver enzyme levels $s^{(4)}$.

Interferon- $\alpha \mathbf{2 a}$ is a recombinant interferon used in various regimens. Effective control of inflammation in $>80 \%$ of patients with persistent Behçet's uveitis has been shown ${ }^{(89)}$. A retrospective study found a $62.5 \%$ response rate to interferon- $\alpha$ 2a used for recalcitrant macular edema ${ }^{(90)}$. However, a randomized controlled intention-to-treat trial that evaluated treatment using interferon- $\alpha 2$ a with corticosteroids compared with no treatment found no significant difference in the reduction of macular edema in chronic noninfectious uveitis at 4 months ${ }^{(91)}$.

The composition of interferon- $\alpha \mathbf{2} \mathbf{b}$ differs from that of interferon $\alpha$-2a by one amino acid. In one small case series, 4 patients with persistent Behçet's uveitis were treated successfully with PEGylated interferon- $\alpha$ $2 \mathrm{~b}^{(92)}$. In another series of 4 patients, a radical improvement in cystoid macular edema secondary to uveitis was observed ${ }^{(93)}$.

Interferon- $\beta$ is approved for the treatment of multiple sclerosis and delivered by subcutaneous or intramuscular injection ${ }^{(94)}$. A few small cohort studies have evaluated the effects of interferon- $\beta$ on uveitis. In patients with multiple sclerosis and uveitis who were receiving interferon- $\beta$, improvement in vision and reduction in macular edema were reported ${ }^{(94)}$. However, more severe uveitis was also observed with interferon- $\beta$ treatment when compared with no treatment ${ }^{(95)}$. A prospective randomized trial with 19 patients that compared interferon- $\beta$ and methotrexate for the treatment of macular edema in intermediate uveitis identified interferon- $\beta$ as the superior treatment after 3 months ${ }^{(96)}$.

\section{Intravenous immunoglobulin}

Intravenous immunoglobulin represents human immunoglobulin (lg) $\mathrm{G}$ acquired through the donation of plasma by healthy donors. It has immunomodulatory functions that affect T- and B-cell responses, and is applied in the treatment of immunodeficiencies and systemic inflammatory diseases ${ }^{(97)}$. In uveitis, intravenous immunoglobulin was found to be effective in controlling inflammation and improving vision in patients with Behçet's disease, birdshot retinochoroidopathy, cancerassociated retinopathy, and other forms of refractory noninfectious uveitis ${ }^{(98-100)}$. Regimens of infusions are repeated every 1-2 months at considerable costs. Possible side effects are eczema, hyperthermia, systemic hypertension, and thrombosis.

\section{T-cell activation blocker}

Abatacept is a selective co-stimulation modulator, created from a portion of human lgG1 fused to the portion of cytotoxic T-lymphocyte-associated protein (CTLA)-4 that binds CD80 or CD86 on antigen-presenting cells, and hence is capable of preventing the co-stimulatory signal required for T-cell activity ${ }^{(101)}$. It is available as subcutaneous or intravenous injections. Despite the early promising data for the treatment of 
refractory uveitis ${ }^{(93)}$, a retrospective study of 21 patients with JIA and refractory uveitis who were receiving abatacept reported remission in just 11 patients, with later recurrence in $8^{(101,102)}$.

\section{Janus kinases inhibitors}

Janus kinases (JAKs) are enzymes that participate in intracellular signaling activated by inflammatory cytokines $^{(103)}$. At least four JAKs exist, namely JAK1, JAK2, JAK3, and TYK2. Tofacitinib and baricitinib are JAK inhibitors that are already being quite widely used in the treatment of rheumatoid arthritis. In one small series of 4 patients with severe JIA-associated uveitis, intraocular inflammation improved in all following initiation of baricitinib or tofacitinib therapy, although joint inflammation improved in just one patient ${ }^{(104)}$. Clinical trials of several JAK inhibitors for noninfectious uveitis are currently in progress.

Despite the vast arsenal of drugs currently available for the treatment of noninfectious uveitis, an ideal therapy that induces sustained remission even after withdrawal is still lacking. The development of biologic response modifiers established a new era in the treatment of uveitis, with a large number of agents on the market and continuous release of more drugs. These drugs are aimed at specifically modulating inflammation to minimize the adverse reactions that may be encountered when using conventional immunomodulatory agents or corticosteroids. As research advances and new discoveries are made on the complex immunologic mechanisms of intraocular inflammation, additional targets are likely to emerge for future biologic therapies of noninfectious uveitis.

\section{ACKNOWLEDGMENT}

The authors wish to thank Ms. Janet Matthews for administrative support in preparing this article.

\section{REFERENCES}

1. de Smet MD, Taylor SR, Bodaghi B, Miserocchi E, Murray PI, Pleyer $\mathrm{U}$, et al. Understanding uveitis: the impact of research on visual outcomes. Prog Retin Eye Res. 2011;30(6):452-70.

2. Gordon DM, McLean JM, Koteen H, Bousquet FP, McCusker WD, Baras I, et al. The use of ACTH and cortisone in ophthalmology. Am J Ophthalmol. 1951;34(12):1675-86.

3. Foster CS, Kothari S, Anesi SD, Vitale AT, Chu D, Metzinger JL, et al. The Ocular Immunology and Uveitis Foundation preferred practice patterns of uveitis management. Surv Ophthalmol. 2016;61(1):1-17.
4. Ritter JM, Lewis LD, Mant TG, Ferro A. A Textbook of clinical pharmacology and therapeutics. 5th ed. London: Hodder Arnold; 2008.

5. Awan MA, Agarwal PK, Watson DG, McGhee CN, Dutton GN. Penetration of topical and subconjunctival corticosteroids into human aqueous humour and its therapeutic significance. $\mathrm{Br}$ J Ophthalmol. 2009;93(6):708-13.

6. Tajika T, Isowaki A, Sakaki H. Ocular distribution of difluprednate ophthalmic emulsion $0.05 \%$ in rabbits. J Ocul Pharmacol Ther. 2011;27(1):43-9.

7. Schallhorn JM, Niemeyer KM, Browne EN, Chhetri P, Acharya NR. Difluprednate for the treatment of uveitic cystoid macular edema. Am J Ophthalmol. 2018;191:14-22.

8. Sheppard JD, Foster CS, Toyos MM, Markwardt K, Da Vanzo R, Flynn TE, et al. Difluprednate $0.05 \%$ versus prednisolone acetate $1 \%$ for endogenous anterior uveitis: pooled efficacy analysis of two phase 3 studies. Ocul Immunol Inflamm. 2019;27(3):484-96.

9. Loteprednol Etabonate US Uveitis Study Group. Controlled evaluation of loteprednol etabonate and prednisolone acetate in the treatment of acute anterior uveitis. Am J Ophthalmol. 1999; 127(5):537-44.

10. Allegri P, Murialdo U, Peri S, Carniglia R, Crivelli MG, Compiano $S$, et al. Randomized, double-blind, placebo-controlled clinical trial on the efficacy of $0.5 \%$ indomethacin eye drops in uveitic macular edema. Invest Ophthalmol Vis Sci. 2014;55(3):1463-70.

11. Isawi H, Dhaliwal DK. Corneal melting and perforation in Stevens Johnson syndrome following topical bromfenac use. J Cataract Refract Surg. 2007;33(9):1644-6.

12. van Minderhout HM, Joosse MV, Grootendorst DC, Schalij-Delfos NE. Adverse reactions following routine anticholinergic eye drops in a paediatric population: an observational cohort study. BM] Open. 2015;5(12):e008798.

13. Mutti DO, Zadnik K, Egashira S, Kish L, Twelker JD, Adams AJ. The effect of cycloplegia on measurement of the ocular components. Invest Ophthalmol Vis Sci. 1994;35(2):515-27.

14. Leder HA, Jabs DA, Galor A, Dunn JP, Thorne JE. Periocular triamcinolone acetonide injections for cystoid macular edema complicating noninfectious uveitis. Am J Ophthalmol. 2011; 152(3):441-8.e2.

15. Sen HN, Vitale S, Gangaputra SS, Nussenblatt RB, Liesegang TL, Levy-Clarke GA, et al. Periocular corticosteroid injections in uveitis: effects and complications. Ophthalmology. 2014;121(11):2275-86.

16. Ferrante P, Ramsey A, Bunce C, Lightman S. Clinical trial to compare efficacy and side-effects of injection of posterior sub-Tenon triamcinolone versus orbital floor methylprednisolone in the management of posterior uveitis. Clin Exp Ophthalmol. 2004;32(6):563-8.

17. Smith JR, George RK, Rosenbaum JT. Lower eyelid herniation of orbital fat may complicate periocular corticosteroid injection. Am J Ophthalmol. 2002;133(6):845-7.

18. Weijtens O, Feron EJ, Schoemaker RC, Cohen AF, Lentjes EG, Romijn FP, et al. High concentration of dexamethasone in aqueous and vitreous after subconjunctival injection. Am J Ophthalmol. 1999;128(2):192-7.

19. Shin JY, Yu HG. Intravitreal triamcinolone injection for uveitic macular edema: a randomized clinical study. Ocul Immunol Inflamm. 2015;23(6):430-6.

20. Jonas JB, Degenring RF, Kreissig I, Akkoyun I, Kamppeter BA. Intraocular pressure elevation after intravitreal triamcinolone acetonide injection. Ophthalmology. 2005;112(4):593-8. 
21. Kok H, Lau C, Maycock N, McCluskey P, Lightman S. Outcome of intravitreal triamcinolone in uveitis. Ophthalmology. 2005; 112(11):1916 e1-7.

22. Thompson JT. Cataract formation and other complications of intravitreal triamcinolone for macular edema. Am J Ophthalmol. 2006;141(4):629-37.

23. Dodwell DG, Krimmel DA, de Fiebre CM. Sterile endophthalmitis rates and particle size analyses of different formulations of triamcinolone acetonide. Clin Ophthalmol. 2015;9:1033-40.

24. Kempen JH, Altaweel MM, Holbrook JT, Jabs DA, Louis TA, Sugar EA, et al.; Multicenter Uveitis Steroid Treatment (MUST) Trial Research Group. Randomized comparison of systemic antiinflammatory therapy versus fluocinolone acetonide implant for intermediate, posterior, and panuveitis: the multicenter uveitis steroid treatment trial. Ophthalmology. 2011;118(10):1916-26.

25. Lowder C, Belfort R Jr, Lightman S, Foster CS, Robinson MR, Schiffman RM, et al. Ozurdex HURON Study Group. Dexamethasone intravitreal implant for noninfectious intermediate or posterior uveitis. Arch Ophthalmol. 2011;129(5):545-53.

26. Thorne JE, Sugar EA, Holbrook JT, Burke AE, Altaweel MM, Vitale AT, et al. Periocular triamcinolone vs.intravitreal triamcinolone vs. intravitreal dexamethasone implant for the treatment of uveitic macular edema: the PeriOcular vs. INTravitreal corticosteroids for uveitic macular edema (POINT) Trial. Ophthalmology. 2019;126(2):283-95.

27. Campochiaro PA, Brown DM, Pearson A, Chen S, Boyer D, Ruiz-Moreno J, et al. Sustained delivery fluocinolone acetonide vitreous inserts provide benefit for at least 3 years in patients with diabetic macular edema. Ophthalmology. 2012;119(10):2125-32.

28. Jaffe GJ. Treatment of non-infectious uveitis that affects the posterior segment with a single intravitreal fluocinolone acetonide insert (FAi) - 3-year results. Invest Ophthalmol Vis Sci. 2019; 60(9):3858.

29. Fishburne BC, Wilson DJ, Rosenbaum JT, Neuwelt EA. Intravitreal methotrexate as an adjunctive treatment of intraocular lymphoma. Arch Ophthalmol. 1997;115(9):1152-6.

30. Kvopka M, Lake SR, Smith JR. Intraocular chemotherapy for vitreoretinal lymphoma: a review. Clin Exp Ophthalmol. 2020; 48(2):240-8.

31. Taylor SR, Banker A, Schlaen A, Couto C, Matthe E, Joshi L, et al. Intraocular methotrexate can induce extended remission in some patients in noninfectious uveitis. Retina. 2013;33(10):2149-54.

32. Nguyen QD, Merrill PT, Clark WL, Banker AS, Fardeau C, Franco $P$, et al. Intravitreal sirolimus for noninfectious uveitis: a Phase III Sirolimus study Assessing double-masKed Uveitis tReAtment (SAKURA). Ophthalmology. 2016;123(11):2413-23.

33. Nakayama M, Keino $H$, Watanabe $T$, Okada AA. Clinical features and visual outcomes of 111 patients with new-onset acute Vogt-Koyanagi-Harada disease treated with pulse intravenous corticosteroids. Br J Ophthalmol. 2019;103(2):274-8.

34. Jabs DA, Rosenbaum JT. Guidelines for the use of immunosuppressive drugs in patients with ocular inflammatory disorders: recommendations of an expert panel. Am J Ophthalmol. 2001; 131(5):679.

35. Kim M), Lee EE, Lee EY, Song YW, Yu HG, Choi Y, et al. Preventive effect of tumor necrosis factor inhibitors versus nonsteroidal anti-inflammatory drugs on uveitis in patients with ankylosing spondylitis. Clin Rheumatol. 2018;37(10):2763-70.

36. Dick AD, Rosenbaum JT, Al-Dhibi HA, Belfort R Jr, Brézin AP, Chee $\mathrm{SP}$, et al. Guidance on noncorticosteroid systemic immunomodulatory therapy in noninfectious uveitis: Fundamentals Of Care for UveitiS (FOCUS) initiative. Ophthalmology. 2018;125(5):757-73.
37. Yates WB, Vajdic CM, Na R, McCluskey PJ, Wakefield D. Malignancy risk in patients with inflammatory eye disease treated with systemic immunosuppressive therapy: a tertiary referral cohort study. Ophthalmology. 2015;122(2):265-73.

38. Kempen JH, Newcomb CW, Foster CS, Jabs DA, Levy-Clarke G, Rosenbaum JT, et al. Risk of overall and cancer mortality after immunosuppression of patients with non-infectious ocular inflammatory diseases. Invest Ophthalmol Vis Sci. 2019;60(9):3854.

39. Ramanan AV, Dick AD, Jones AP, McKay A, Williamson PR, Compeyrot-Lacassagne $S$, et al. Adalimumab plus methotrexate for uveitis in juvenile idiopathic arthritis. N Engl J Med. 2017;376(17):1637-46.

40. Bichler J, Benseler SM, Krumrey-Langkammerer M, Haas JP, Hügle B. Leflunomide is associated with a higher flare rate compared to methotrexate in the treatment of chronic uveitis in juvenile idiopathic arthritis. Scand J Rheumatol. 2015;44(4):280-3.

41. Gangaputra S, Newcomb CW, Liesegang TL, Kaçmaz RO, Jabs DA, Levy-Clarke GA, et al. Methotrexate for ocular inflammatory diseases. Ophthalmology. 2009;116(11):2188-98 e1.

42. Gangaputra SS, Newcomb CW, Joffe MM, Dreger K, Begum H, Artornsombudh $\mathrm{P}$, et al. Comparison between methotrexate and mycophenolate mofetil monotherapy for the control of noninfectious ocular inflammatory diseases. Am J Ophthalmol. 2019; 208:68-75.

43. Pasadhika S, Kempen JH, Newcomb CW, Liesegang TL, Pujari SS, Rosenbaum JT, et al. Azathioprine for ocular inflammatory diseases. Am J Ophthalmol. 2009;148(4):500-9 e2.

44. Baker KB, Spurrier NJ, Watkins AS, Smith JR, Rosenbaum JT. Retention time for corticosteroid-sparing systemic immunosuppressive agents in patients with inflammatory eye disease. Br J Ophthalmol. 2006;90(12):1481-5.

45. Daniel E, Thorne JE, Newcomb CW, Pujari SS, Kaçmaz RO, LevyClarke GA, et al. Mycophenolate mofetil for ocular inflammation. Am J Ophthalmol. 2010;149(3):423-32.e1-2.

46. Coulthard SA, Hall AG. Recent advances in the pharmacogenomics of thiopurine methyltransferase. Pharmacogenomics J. 2001;1(4):254-61.

47. Kaçmaz RO, Kempen JH, Newcomb C, Daniel E, Gangaputra S, Nussenblatt RB, et al. Cyclosporine for ocular inflammatory diseases. Ophthalmology. 2010;117(3):576-84.

48. Murphy CC, Greiner K, Plskova J, Duncan L, Frost NA, Forrester $\mathrm{JV}$, et al. Cyclosporine vs tacrolimus therapy for posterior and intermediate uveitis. Arch Ophthalmol. 2005;123(5):634-41.

49. Pujari SS, Kempen JH, Newcomb CW, Gangaputra S, Daniel E, Suhler EB, et al. Cyclophosphamide for ocular inflammatory diseases. Ophthalmology. 2010;117(2):356-65.

50. Goldstein DA, Fontanilla FA, Kaul S, Sahin O, Tessler HH. Longterm follow-up of patients treated with short-term high-dose chlorambucil for sight-threatening ocular inflammation. Ophthalmology. 2002;109(2):370-7.

51. Birnbaum AD, Oh F, Sahin O, Little DM, Tessler HH, Goldstein DA. Chlorambucil and malignancy. Ophthalmology. 2010;117(7):1466- e1.

52. Benitez Del Castillo JM, Garcia-Sanchez J, Iradier T, Bañares A. Sulfasalazine in the prevention of anterior uveitis associated with ankylosing spondylitis. Eye (Lond). 2000;14(3):340-3.

53. Kruh JN, Yang P, Suelves AM, Foster CS. Infliximab for the treatment of refractory noninfectious uveitis: a study of 88 patients with long-term follow-up. Ophthalmology. 2014;121(1):358-64.

54. Kempen JH, Daniel E, Dunn JP, Foster CS, Gangaputra S, Hanish A, et al. Overall and cancer related mortality among patients with ocular inflammation treated with immunosuppressive drugs: retrospective cohort study. BMJ. 2009;339:b2480. 
55. Nyboe Andersen NN, Pasternak B, Basit S, Andersson M, Svanström $\mathrm{H}$, Caspersen S, et al. Association between tumor necrosis factor-alpha antagonists and risk of cancer in patients with inflammatory bowel disease. JAMA. 2014;311(23):2406-13.

56. Maleki A, Sahawneh HF, Ma L, Meese H, He Y, Foster CS. Infliximab therapy in patients with noninfectious intermediate uveitis resistant to conventional immunomodulatory therapy. Retina. 2017;37(5):836-43.

57. Fabiani C, Vitale A, Rigante D, Emmi G, Bitossi A, Lopalco G, et al. Comparative efficacy between adalimumab and infliximab in the treatment of non-infectious intermediate uveitis, posterior uveitis, and panuveitis: a retrospective observational study of 107 patients. Clin Rheumatol. 2019;38(2):407-15.

58. Cecchin V, Zannin ME, Ferrari D, Pontikaki I, Miserocchi E, Paroli MP, et al. Longterm safety and efficacy of adalimumab and infliximab for uveitis associated with juvenile idiopathic arthritis. J Rheumatol. 2018;45(8):1167-72.

59. Jaffe G), Dick AD, Brézin AP, Nguyen QD, Thorne JE, Kestelyn P, et al. Adalimumab in patients with active noninfectious uveitis. N Engl J Med. 2016;375(10):932-43.

60. Nguyen QD, Merrill PT, Jaffe G), Dick AD, Kurup SK, Sheppard J, et al. Adalimumab for prevention of uveitic flare in patients with inactive non-infectious uveitis controlled by corticosteroids (VISUAL II): a multicentre, double-masked, randomised, placebocontrolled phase 3 trial. Lancet. 2016;388(10050):1183-92.

61. Horton S, Jones AP, Guly CM, Hardwick B, Beresford MW, Lee $\mathrm{RW}$, et al. Adalimumab in juvenile-idiopathic arthritis-associated uveitis (JIA-U): 5-year follow-up of the Bristol participants of the SYCAMORE trial. Am J Ophthalmol. 2019;207:170-4.

62. Suhler EB, Adán A, Brézin AP, Fortin E, Goto H, Jaffe G), et al. Safety and efficacy of adalimumab in patients with noninfectious uveitis in an ongoing open-label study: VISUAL III. Ophthalmology. 2018;125(7):1075-87.

63. Fabiani C, Vitale A, Emmi G, Bitossi A, Lopalco G, Sota J, et al. Long-term retention rates of adalimumab and infliximab in non-infectious intermediate, posterior, and panuveitis. Clin Rheumatol. 2019;38(1):63-70.

64. Baert F, Noman M, Vermeire S, Van Assche G, D'Haens G, Carbonez A, et al. Influence of immunogenicity on the longterm efficacy of infliximab in Crohn's disease. N Engl J Med. 2003;348(7):601-8.

65. Cordero-Coma M, Calvo-Río V, Adán A, Blanco R, Álvarez-Castro C, Mesquida M, et al. Golimumab as rescue therapy for refractory immune-mediated uveitis: a three-center experience. Mediators Inflamm. 2014;2014:717598.

66. Fabiani C, Sota J, Rigante D, Vitale A, Emmi G, Vannozzi L, et al. Rapid and sustained efficacy of golimumab in the treatment of multirefractory uveitis associated with Behçet's disease. Ocul Immunol Inflamm. 2019;27(1):58-63.

67. van Bentum RE, Heslinga SC, Nurmohamed MT, Gerards AH, Griep EN, Koehorst C, et al. Reduced occurrence rate of acute anterior uveitis in ankylosing spondylitis treated with golimumab - The GO-EASY study. J Rheumatol. 2019;46(2):153-9.

68. Miserocchi E, Modorati G, Pontikaki I, Meroni PL, Gerloni V. Longterm treatment with golimumab for severe uveitis. Ocul Immunol Inflamm. 2014;22(2):90-5.

69. Rudwaleit M, Rosenbaum JT, Landewé R, Marzo-Ortega H, Sieper J, van der Heijde D, et al. Observed incidence of uveitis following certolizumab pegol treatment in patients with axial spondyloarthritis. Arthritis Care Res (Hoboken). 2016;68(6):838-44.

70. Tosi GM, Sota J, Vitale A, Rigante D, Emmi G, Lopalco G, et al. Efficacy and safety of certolizumab pegol and golimumab in the treatment of non-infectious uveitis. Clin Exp Rheumatol. 2019;37(4):680-3.

71. Smith JA, Thompson DJ, Whitcup SM, Suhler E, Clarke G, Smith S, et al. A randomized, placebo-controlled, double-masked clinical trial of etanercept for the treatment of uveitis associated with juvenile idiopathic arthritis. Arthritis Rheum. 2005;53(1):18-23.

72. Smith JR, Levinson RD, Holland GN, Jabs DA, Robinson MR, Whitcup SM, et al. Differential efficacy of tumor necrosis factor inhibition in the management of inflammatory eye disease and associated rheumatic disease. Arthritis Rheum. 2001;45(3):252-7.

73. Fabiani C, Vitale A, Rigante D, Emmi G, Lopalco G, Di Scala G, et al. The presence of uveitis is associated with a sustained response to the interleukin (IL)-1 inhibitors anakinra and canakinumab in Behçet's disease. Ocul Immunol Inflamm. 2020;28(2):298-304.

74. Sota J, Vitale A, Insalaco A, Sfriso P, Lopalco G, Emmi G, et al. Safety profile of the interleukin-1 inhibitors anakinra and canakinumab in real-life clinical practice: a nationwide multicenter retrospective observational study. Clin Rheumatol. 2018;37(8):2233-40.

75. Tugal-Tutkun I, Kadayifcilar S, Khairallah M, Lee SC, Ozdal P, Özyazgan Y, et al. Safety and efficacy of gevokizumab in patients with Behçet's disease uveitis: results of an exploratory phase 2 study. Ocul Immunol Inflamm. 2017;25(1):62-70.

76. Tugal-Tutkun I, Pavesio C, De Cordoue A, Bernard-Poenaru O, Gül A. Use of gevokizumab in patients with Behçet's disease uveitis: an international, randomized, double-masked, placebo-controlled study and open-label extension study. Ocul Immunol Inflamm. 2018;26(7):1023-33.

77. Atienza-Mateo B, Calvo-Río V, Beltrán E, Martinéz-Costa L, Valls-Pascual E, Hernández-Garfella M, et al. Anti-interleukin 6 receptor tocilizumab in refractory uveitis associated with Behçet's disease: multicentre retrospective study. Rheumatology (Oxford). 2018;57(5):856-64.

78. Ramanan AV, Dick AD, Guly C, McKay A, Jones AP, Hardwick B, et al. Tocilizumab in patients with anti-TNF refractory juvenile idiopathic arthritis-associated uveitis (APTITUDE): a multicentre, single-arm, phase 2 trial. Lancet Rheumatol. 2020;2(3):e135-e41.

79. Mesquida M, Molins B, Llorenç V, Hernández MV, Espinosa G, Sainz de la Maza M, et al. Twenty-four month follow-up of tocilizumab therapy for refractory uveitis-related macular edema. Retina. 2018;38(7):1361-70.

80. Sepah YJ, Sadiq MA, Chu DS, Dacey M, Gallemore R, Dayani P, et al. Primary (Month-6) Outcomes of the STOP-Uveitis Study: Evaluating the Safety, Tolerability, and Efficacy of Tocilizumab in Patients With Noninfectious Uveitis. Am J Ophthalmol. 2017;183:71-80.

81. Vegas-Revenga N, Calvo-Río V, Mesquida M, Adán A, Hernández MV, Beltran E, et al. Anti-IL6-receptor tocilizumab in refractory and noninfectious uveitic cystoid macular edema: multicenter study of 25 patients. Am J Ophthalmol. 2019;200:85-94.

82. Heissigerová J, Callanan D, de Smet MD, Srivastava SK, Karkanová M, Garcia-Garcia O, et al. Efficacy and safety of sarilumab for the treatment of posterior segment noninfectious uveitis (SARIL-NIU): the phase 2 SATURN study. Ophthalmology. 2019;126(3):428-37.

83. Dick AD, Tugal-Tutkun I, Foster S, Zierhut M, Melissa Liew SH, Bezlyak V, et al. Secukinumab in the treatment of noninfectious uveitis: results of three randomized, controlled clinical trials. Ophthalmology. 2013;120(4):777-87.

84. Letko E, Yeh S, Foster CS, Pleyer U, Brigell M, Grosskreutz CL; AIN457A2208 Study Group. Efficacy and safety of intravenous secukinumab in noninfectious uveitis requiring steroid-sparing immunosuppressive therapy. Ophthalmology. 2015;122(5):939-48. 
85. Heiligenhaus A, Miserocchi E, Heinz C, Gerloni V, Kotaniemi K. Treatment of severe uveitis associated with juvenile idiopathic arthritis with anti-CD20 monoclonal antibody (rituximab). Rheumatology (Oxford). 2011;50(8):1390-4.

86. Lasave AF, You C, Ma L, Abusamra K, Lamba N, Valdes Navarro $\mathrm{M}$, et al. Long-term outcomes of rituximab therapy in patients with non-infectious posterior uveitis refractory to conventional immunosuppressive therapy. Retina. 2018;38(2):395-402.

87. Suhler EB, Lim LL, Beardsley RM, Giles TR, Pasadhika S, Lee ST, et al. Rituximab therapy for refractory orbital inflammation: results of a phase 1/2, dose-ranging, randomized clinical trial. JAMA Ophthalmol. 2014;132(5):572-8.

88. Suhler EB, Lim LL, Beardsley RM, Giles TR, Pasadhika S, Lee ST, et al. Rituximab therapy for refractory scleritis: results of a phase $1 /$ ll dose-ranging, randomized, clinical trial. Ophthalmology. 2014;121(10):1885-91.

89. Sobaci G, Erdem U, Durukan AH, Erdurman C, Bayer A, Köksal S, et al. Safety and effectiveness of interferon alpha-2a in treatment of patients with Behçet's uveitis refractory to conventional treatments. Ophthalmology. 2010;117(7):1430-5.

90. Deuter CM, Kötter I, Günaydin I, Stübiger N, Doycheva DG, Zierhut M. Efficacy and tolerability of interferon alpha treatment in patients with chronic cystoid macular oedema due to noninfectious uveitis. Br J Ophthalmol. 2009;93(7):906-13.

91. Fardeau C, Simon A, Rodde B, Viscogliosi F, Labalette P, Looten $\mathrm{V}$, et al. Interferon-alpha2a and systemic corticosteroid in monotherapy in chronic uveitis: results of the randomized controlled BIRDFERON study. Am J Ophthalmol. 2017;177:182-94.

92. Celiker H, Kazokoglu H, Direskeneli H. Long-term efficacy of pegylated interferon alpha-2b in Behçet's uveitis: a small case series. Ocul Immunol Inflamm. 2019;27(1):15-22.

93. Butler NJ, Suhler EB, Rosenbaum JT. Interferon alpha $2 b$ in the treatment of uveitic cystoid macular edema. Ocul Immunol Inflamm. 2012;20(2):86-90.

94. Becker MD, Heiligenhaus A, Hudde T, Storch-Hagenlocher B, Wildemann B, Barisani-Asenbauer T, et al. Interferon as a treatment for uveitis associated with multiple sclerosis. $\mathrm{Br}$ J Ophthalmol. 2005;89(10):1254-7.

95. Jouve L, Benrabah R, Héron E, Bodaghi B, Le Hoang P, Touitou V. Multiple sclerosis-related uveitis: does MS treatment affect uveitis course? Ocul Immunol Inflamm. 2017;25(3):302-7.

96. Mackensen F, Jakob E, Springer C, Dobner BC, Wiehler U, Weimer $\mathrm{P}$, et al. Interferon versus methotrexate in intermediate uveitis with macular edema: results of a randomized controlled clinical trial. Am J Ophthalmol. 2013;156(3):478-86.e1.

97. Schwab l, Nimmerjahn F. Intravenous immunoglobulin therapy: how does IgG modulate the immune system? Nat Rev Immunol. 2013;13(3):176-89.

98. Seider N, Beiran I, Scharf J, Miller B. Intravenous immunoglobulin therapy for resistant ocular Behçet's disease. Br J Ophthalmol. 2001;85(11):1287-8.

99. LeHoang P, Cassoux N, George F, Kullmann N, Kazatchkine MD. Intravenous immunoglobulin (IVlg) for the treatment of birdshot retinochoroidopathy. Ocul Immunol Inflamm. 2000;8(1):49-57.

100. Onal S, Foster CS, Ahmed AR. Efficacy of intravenous immunoglobulin treatment in refractory uveitis. Ocul Immunol Inflamm. 2006;14(6):367-74.

101. Tappeiner C, Miserocchi E, Bodaghi B, Kotaniemi K, Mackensen F, Gerloni V, et al. Abatacept in the treatment of severe, longstanding, and refractory uveitis associated with juvenile idiopathic arthritis. J Rheumatol. 2015;42(4):706-11.

102. Zulian F, Balzarin M, Falcini F, Martini G, Alessio M, Cimaz R, et al. Abatacept for severe anti-tumor necrosis factor alpha refractory juvenile idiopathic arthritis-related uveitis. Arthritis Care Res. 2010;62(6):821-5.

103. Fragoulis GE, Mclnnes IB, Siebert S. JAK-inhibitors. New players in the field of immune-mediated diseases, beyond rheumatoid arthritis. Rheumatology (Oxford). 2019;58(Suppl 1):i43-54.

104. Miserocchi E, Giuffrè C, Cornalba M, Pontikaki l, Cimaz R. JAK inhibitors in refractory juvenile idiopathic arthritis-associated uveitis. Clin Rheumatol. 2020;39(3):847-51. 